\title{
Respiratory viruses from hospitalized children with severe pneumonia in the Philippines
}

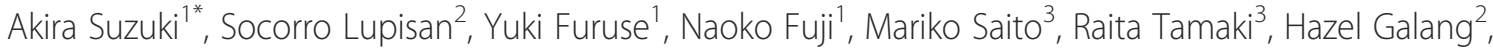 \\ Lydia Sombrero ${ }^{2}$, Melisa Mondoy ${ }^{2}$, Rapunzel Aniceto ${ }^{3}$, Remigio Olveda ${ }^{2}$ and Hitoshi Oshitani ${ }^{1}$
}

\begin{abstract}
Background: Pneumonia remains a leading cause of child death in developing countries. The viruses in severe pneumonia remain poorly defined.

Methods: The study was conducted at the Eastern Visayas Regional Medical Center in Tacloban City, Philippines from May 2008 to May 2009. Patients aged 8 days to 13 years old who were admitted to the Department of Pediatrics with severe pneumonia were enrolled for the study. Upon admission, polymerase chain reaction was performed using nasopharyngeal swabs and blood cultures to detect respiratory viruses and bacteria, respectively.

Result: Among the 819 patients enrolled, at least one virus was detected in 501 cases (61.2\%). In addition, 423 cases were positive for a single virus while bacteria were detected in the blood culture sample of 31 cases. The most commonly detected viruses were human rhinoviruses $(n=189)$, including types $A(n=103), B(n=17)$, and C $(n=69)$, and respiratory syncytial virus (RSV) $(n=165)$. Novel viruses such as human metapneumovirus, human coronavirus NL63, human bocavirus, and human polyomaviruses WU and KI were also detected. There were 70 deaths, and one or more viruses were detected in 35 (50\%) of these cases. Positivity only for influenza A virus (OR = $4.3,95 \% \mathrm{Cl}=1.3-14.6)$ was significantly associated with fatal outcome. From the blood culture, Burkholderia cepacia group $(n=9)$, Streptococcus pneumoniae $(n=4)$, Staphylococcus aureus $(n=4)$, Haemophilus influenzae $(n=1)$, and Salmonella C1 $(n=1)$ were also isolated.

Conclusion: Viruses were commonly detected in children with severe pneumonia in the Philippines. Hence, viral etiologies should be considered while developing better effective strategies to reduce child pneumonia-related deaths in developing countries.
\end{abstract}

\section{Background}

Infant and under-five mortality rates are commonly considered as important health indicators. In 2000, the United Nations introduced the Millennium Development Goal 4 (MDG4) to reduce under-five mortality by two-thirds between 1990 and 2015. The under-five mortality rate has steadily decreased from 90 per 1000 live births in 1990 to 65 per 1000 live births in 2008 [1]. However, the rate remains high in many developing countries[1], and pneumonia is still the leading cause of childhood mortality $[2,3]$, particularly in the developing countries. It is estimated that approximately 2 million children die from pneumonia annually, and $90 \%$ of these deaths occur in developing

\footnotetext{
* Correspondence: suzukia@med.tohoku.ac.jp

'Department of Virology, Tohoku University Graduate School of Medicine,

2-1 Seiryo-machi, Aoba-ku, Sendai 980-8575, Japan

Full list of author information is available at the end of the article
}

countries [2-4]. However, viral etiologies may be underestimated in cases of severe pneumonia in the resourcelimited countries with limited diagnostic facilities. The role of viral pathogens in severe pneumonia has come into prominence as the role of bacterial infection decreases through early case detection, appropriate antibiotic treatment [5] and introduction of conjugate vaccines.

Historically, the common viruses most closely associated with childhood pneumonia have included influenza virus (Flu), respiratory syncytial virus (RSV), parainfluenza virus (PIV), and adenovirus (AdV). The development of molecular techniques facilitated the detection of novel viruses in patients with respiratory infections. Human metapneumovirus (hMPV) was first documented in 2001 [6]. Since then, a series of human coronaviruses $(\mathrm{HCoVs})$, including NL-63 [7], -NH [8], and -HKU-1 [9], a new genogroup of human rhinoviruses (HRVs) called type-C rhinoviruses 
[10], human bocavirus (HBoV) [11], and human polyomaviruses WU (WUV) and KI (KIV) [12,13] have been reported. We recently demonstrated the presence of hMPV, HCoV-NL63, HCoV-HKU1, HBoV, WUV, and KIV in patients with influenza-like illness in the Philippines [14], but were unable to assess their clinical significance in children with pneumonia. The etiological roles of these novel viruses remain undefined.

In this prospective study, we investigated the association between presence of a virus and severity of disease in hospitalized children with severe pneumonia to provide an indication of causality. With this aim, we detected viral as well as bacterial pathogens in children hospitalized with severe community-acquired pneumonia and assessed the clinical significance of these pathogens.

\section{Methods}

\section{Study site}

The study was conducted at the Eastern Visayas Regional Medical Center (EVRMC) in Tacloban City, Philippines. Tacloban City is the capital of Leyte Province and the regional center for Region VIII, also known as "Eastern Visayas". The climate of Leyte Province is classified as tropical monsoon, and it usually rains throughout the year with higher rainfall between November and January. Region VIII consists of two main islands, Leyte and Samar, with a population of approximately 4 million (See Additional file 1a and b: Map of the Philippines and Region VIII). This region is generally economically less developed, and the estimated poverty incidence (the proportion of people in the population whose income is lesser than the cost of basic needs) was $40.7 \%$, compared to the national estimate of $26.9 \%$ [15]. The estimated under-five mortality rate in 2008 was 64 per 1000 live births in Region VIII, which is significantly higher than the national average of 28 deaths per 1000 live births in urban areas and 46 deaths per 1000 live births in rural areas of the Philippines [16]. EVRMC has a 250-bed capacity including 50 pediatric beds and is the only tertiary care government hospital in Region VIII. Patients were referred from all over the region, but majority of the patients were from Leyte Province, particularly from Tacloban City.

\section{Study patients and case definitions}

From May 2008 to May 2009, patients aged 8 days to 13 years old who visited the Emergency Room of EVRMC and presented with acute respiratory infection were evaluated according to IMCI guidelines [17]. Patients assessed to have severe pneumonia requiring hospitalization were recruited for participation in the study. The definition of severe pneumonia was based on IMCI guidelines. All cases were screened with the presence of cough or difficulty of breathing as the initial assessment. For patients between 8 days to less than 2 months old, entry criteria included fast breathing (more than 60 breaths/min), chest indrawing, cyanosis, or an inability to drink or suck. For patients between 2 months to less than 5 years old, entry criteria included chest indrawing, cyanosis, or an inability to drink or suck. For patients between 5 to 13 years old, entry criteria included co-morbid illness (including malnutrition), failure to feed, moderate to severe dehydration, signs of respiratory failure (chest indrawing, cyanosis, apnea, or sensorial change), or complications such as plural effusion and pneumothorax. The exclusion criteria included patients less than 7 days old to exclude perinatal infection, patients admitted to any other department of EVRMC for another illness and who had developed symptoms of pneumonia while in hospital, or patients who had been admitted to another hospital within the last 3 days prior to present admission to EVRMC to exclude nosocomial infection.

This was a prospective observational study. The antibiotics provided were based on the guidelines of the Philippine Pediatric Society [18]. As supportive therapy, oxygen was provided using a nasal catheter or oxygen mask. Endotracheal intubation was done if necessary and hooked to a manual ambu bag as there was no mechanical ventilator in the pediatric ICU of EVRMC.

\section{Patient information}

The staff of the Pediatric Department were retrained on the IMCI-Acute Respiratory Infection case management protocol prior to initiation of the study [19]. Trained project pediatricians and nurses collected relevant clinical information on admission including information on antibiotics administered during the current episode. They also recorded signs, symptoms and vital signs of enrolled patients twice a day. Thereafter, patient outcomes were classified using the following five categories on the basis of their condition on discharge: "Discharged improved," "Discharged against medical adviceImproved," "Discharged against medical advice-deteriorating," "Died," and "Others." "Others" included those who absconded or were transferred to another hospital. For data analysis, we combined "Discharged against medical advice-deteriorating" and "Died" as the fatal or life-threatening outcome group as we did in previous "Bohol study" in the Philippines [20-22].

\section{Radiological assessment}

Anteroposterior and lateral chest radiographs were taken upon admission. Interpretation was performed by a designated radiologist trained in the standard interpretation of chest radiographs for the diagnosis of childhood pneumonia, as developed by the WHO Pneumonia Vaccine Trial Investigators' Group [23]. 


\section{Detection of viruses}

Nasopharyngeal swabs were taken from patients using EX-swab 002 (DENKA SEIKEN, Tokyo, Japan), stirred in $3 \mathrm{ml}$ of viral transport medium (VTM), and stored at $4^{\circ} \mathrm{C}$ until sample transport. Swabs were shipped to the Research Institute for Tropical Medicine (RITM) for virus detection twice a week using the recommended biological transport containers with temperatures maintained at $4{ }^{\circ} \mathrm{C}$. The specimens were subjected to PCR within 10 days after sample collection. Common respiratory viruses were targeted. RNA and DNA present in $100 \mu \mathrm{l}$ of VTM supernatant were purified using the QIAamp MinElute Virus Spin Kit (Qiagen, Hilden, Germany). To synthesize complementary DNA, $11 \mu \mathrm{l}$ of the final extract was used as a template with superscript III, random hexamers, and RNase inhibitor (all obtained from Invitrogen, Carlsbad, CA). PCR was performed to detect FluA, FluB, RSVs, hMPV, HCoVs, HBoV, WUV, and KIV as previously described [14]. For PIV-1, -2 , and -3 , the hemagglutininneuraminidase region was amplified [24]. For HRVs, the $5 /$ noncoding region was amplified using the primer pairs DK001 [25] and DK004 [26]. Negative and positive controls were added in each PCR run. For the purpose of our routine quality control, PCR for all positive samples were double checked in the Department of Virology, Tohoku University Graduate School of Medicine.

Serotypes or genotypes of RSVs, HRVs, and AdVs were determined by sequencing the hypervariable region of the G protein gene for RSVs [27], the VP4-VP2 region of HRVs [28], and the hexon region of AdVs [29]. Sequencing was performed using ABI 3730xl with BigDye version 1.1 (Applied Biosystems, Carlsbad, CA), and sequence results were analyzed by MEGA ver. 4 [30] with reference strains from Genbank.

\section{Detection of bacteria}

Blood culture for bacteria was performed by trained medical technologists in EVRMC as previously described [22]. On admission, $1 \mathrm{ml}$ of venous blood was collected aseptically and inoculated into a bottle containing $20 \mathrm{ml}$ of brain-heart infusion broth with $1 \%$ gelatin, $0.125 \%$ sodium polyanethol sulfonate, and $0.1 \%$ agar. Samples were incubated at $36^{\circ} \mathrm{C}$ for seven days and subcultures were made on sheep blood, chocolate, and MacConkey agar plates after 18 hours and 3, 5, and 7 days of inoculation. Plates were cultured at $36^{\circ} \mathrm{C}$ in a candle jar for 2 days. Drug sensitivity testing for all isolates was performed by the disk diffusion method based on Clinical Laboratory Standard Institute (CLSI) guidelines and resistant isolates were tested by the E-test for minimum inhibitory concentration (MIC) determination. All isolates were stored in the skim milk at $-20^{\circ} \mathrm{C}$ and transported to RITM for confirmatory tests. Final identification was done in the Department of Microbiology, RITM. This department has been participating in the College of American Pathologists Proficiency Tests for Microbiology, and it has consistently passed the External Quality Assurance System (EQAS) since 2008. For confirmatory test for Burkholderia cepacia group, isolates were sent to Miroku Medical Laboratory in Nagano, Japan, and underwent sequencing for 16S rRNA.

\section{Statistical analysis}

All data was encoded into the FileMaker database (FileMaker CA, USA), and statistical analysis was performed using SPSS 18.0J (SPSS Japan, Tokyo, Japan). Univariate analysis was used to determine the viral pathogens associated with fatal outcomes. The risk of fatal outcome for each detected virus and virus combination was evaluated by estimating the odds ratio (OR) based on categorization in the "Discharged against medical advice-deteriorating" or "Died" category.

\section{Ethical consideration}

The study protocol was approved by the Institutional Review Board of Tohoku University Graduate School of Medicine, RITM, and EVRMC. The parents or guardians gave written informed consent for their children to participate in the study.

\section{Results}

\section{Patients' profiles}

During the 13-month study period, a total of 1242 patients were screened and 1043 met with the inclusion criteria. Of the 1043 patients, 224 refused to participate. A total of 819 cases were subsequently enrolled in the study. Background information and physical findings of the 819 cases are summarized in Table 1. Among the 224 patients whose parents or guardians refused enrolment, we collected data only from 48 patients screened since December 2008. The major reason for the refusal was that parents did not permit to collect blood samples from their children $(73.0 \%[35 / 48])$. The ratio of severe pneumonia (67\% [32/48]), very severe pneumonia (23\% [11/48]), and others $(10 \%$ [5/48]) was $67: 23: 10$. This ratio was different from that of the enrolled patients (50:44:6). The median age was 9.0 months, and the age distribution was skewed towards younger age groups (See Additional file 2: Age distribution of children hospitalized with severe pneumonia in Eastern Visayas Regional Medical Center, May 2008 to May 2009).

Wheezing was observed in half of the patients $(\mathrm{n}=418$, $51.1 \%)$. One hundred seventy five patients $(21.4 \%)$ had interstitial infiltrates on chest $\mathrm{x}$-ray, and 157 patients (19.2\%) had consolidation. The median time interval between the onset of illness and admission was 4 days. Furthermore, $32.2 \%$ patients $(\mathrm{n}=264)$ had received antibiotics prior to hospital admission. Since $10.7 \%(\mathrm{n}=88)$ of the cases deteriorated during hospital admission, they were 
Table 1 Background and Clinical Information of children hospitalized with severe pneumonia, Eastern Visayas Regional Medical Center, May 2008 to May 2009

\begin{tabular}{|c|c|c|}
\hline & $\mathbf{n}$ & Percentage \\
\hline \multicolumn{3}{|l|}{ Demographic information } \\
\hline Male & 446 & $54.5 \%$ \\
\hline Female & 373 & $45.5 \%$ \\
\hline \multicolumn{3}{|l|}{ Age in months* } \\
\hline Median (Interquartile range) & $9(3-20)$ & \\
\hline \multicolumn{3}{|l|}{ Age groups* } \\
\hline $0 \sim 5 \mathrm{mo}$ & 290 & $35.5 \%$ \\
\hline $6 \sim 11 \mathrm{mo}$ & 177 & $21.6 \%$ \\
\hline 1yo & 171 & $20.9 \%$ \\
\hline 2 ууо & 78 & $9.5 \%$ \\
\hline 3 6уо & 75 & $9.2 \%$ \\
\hline 7yo or higher & 27 & $3.3 \%$ \\
\hline \multicolumn{3}{|l|}{ Initial Diagnosis } \\
\hline Very Severe Pneumonia & 364 & $44.4 \%$ \\
\hline Severe Pneumonia & 410 & $50.1 \%$ \\
\hline Neonatal Pneumonia and others & 45 & $5.5 \%$ \\
\hline \multicolumn{3}{|l|}{ Clinical information } \\
\hline \multicolumn{3}{|l|}{ Symptoms and Signs on admission } \\
\hline Cough & 818 & $99.9 \%$ \\
\hline Chest indrawing & 808 & $98.7 \%$ \\
\hline Decrease in breath sound* & 796 & $97.3 \%$ \\
\hline Difficulty of breathing & 671 & $81.9 \%$ \\
\hline Wheeze* & 418 & $51.1 \%$ \\
\hline Cyanosis* & 62 & $7.6 \%$ \\
\hline Drowsiness* & 35 & $4.3 \%$ \\
\hline Convulsion & 50 & $6.1 \%$ \\
\hline \multicolumn{3}{|l|}{ Chest X-ray } \\
\hline interstitial infiltrate & 111 & $13.6 \%$ \\
\hline consolidation & 93 & $11.4 \%$ \\
\hline interstitial infiltrate and consolidation & 64 & $7.8 \%$ \\
\hline \multicolumn{3}{|l|}{ Outcome } \\
\hline Discharged & 550 & $67.2 \%$ \\
\hline $\begin{array}{l}\text { Discharged against medical advice- } \\
\text { Improved }\end{array}$ & 151 & $18.4 \%$ \\
\hline $\begin{array}{l}\text { Discharged against medical advice- } \\
\text { Deteriorate }\end{array}$ & 18 & $2.2 \%$ \\
\hline Died & 70 & $8.5 \%$ \\
\hline Others & 30 & $3.6 \%$ \\
\hline \multicolumn{3}{|l|}{ Time interval between Onset and Visit ${ }^{\#}$} \\
\hline Median (Interquartile range) & $4(3-7)$ & (unit=days) \\
\hline Antibiotic prior to admission & 264 & $32.2 \%$ \\
\hline Total & 819 & \\
\hline
\end{tabular}

*Data was missing for one case.

"Data was missing for two cases. classified as "Died" ( $\mathrm{n}=70,8.5 \%)$ or "Discharged against medical advice-deteriorating" ( $\mathrm{n}=18,2.2 \%)$.

\section{Detection of viruses}

Among the 819 respiratory samples, 501 samples (61.2\%) were positive for at least one virus. These included 423 cases (51.6\%); 72 cases (8.8\%); and 6 cases $(0.7 \%)$ who were positive for one, two viruses, and three viruses, respectively (Table 2). The most common respiratory virus detected was HRV (total positive cases, 30.5\% [250/819]), including type A (HRV-A) (total, 17.3\% [142/819]), type B (HRV-B) (total, 3.1\% [25/819]), and type C (HRV-C) (total, $10.1 \%$ [83/819]). The second most common virus was RSV (total, 24.1\% [198/819]), most commonly subtype A (RSV-A) (97\% [195/198]). Different subtypes of AdVs (total, 4.0\% [33/819]) were detected: AdV-7 (total, 10; single, 6), AdV-3 (total, 8; single, 5), AdV-6 (total, 6; single 1), AdV-2 (total, 2; single, 1), AdV-4 (total, 2; single, 1), AdV5 (total, 2; single, 1), Adv-41 (total, 2; single, 0), and Adv12 (total, 1; single, 0). All cases of FluA (total, 2.2\% [18/ 819]) were seasonal influenza A virus (H1N1). In terms of multiple infection, more than $50 \%$ of samples positive for AdVs (54.5\% [18/33]), WUV (64.0\% [16/25]), HBoV (71.4\% [5/7]), FluB (72.7\% [8/11]), and KIV (75.0\% [3/4]) were positive along with other viruses (Table 2).

\section{Seasonality of the viruses}

The monthly rainfall precipitation and case counts are shown in Figure 1. During the study period, the number of enrolled cases gradually increased and peaked in October, whereas the rainfall increased beginning in October and peaked in December. For viruses detected in more than 20 cases, the monthly distributions of single and multiple virus-positive cases were shown in Figures 2A -2F. RSV-A positivity peaked in October 2009 concurrently with the increase in rainfall in Tacloban City (Figures 1 and 2A). Conversely, there was a cluster of hMPVpositive cases in March which was a month of low rainfall (Figure 2B). Although AdVs were detected intermittently, there was a peak in the number of AdV cases $(n=11)$ in December (Figure $2 C)$ during which AdV-7 $(n=6)$, AdV$6(\mathrm{n}=3), \operatorname{AdV}-4(\mathrm{n}=1)$, and $\operatorname{AdV}-12(\mathrm{n}=1)$ were detected. There was a cluster of HRV-B-positive cases at the same time as the peak of RSV-A positive cases (Figures $2 \mathrm{~A}$ and $\mathrm{E}$ ), whereas HRV-A and HRV-C were detected throughout the study period (Figures 2D and F).

\section{Associated risk with viral pathogens}

Based on previous "Bohol study" in the Philippines, we combined "Discharged against medical advicedeteriorating" and "Died" as the fatal outcome group, as we mentioned earlier, this group denotes the lifethreatening cases. Since EVRMC is the only tertiary care government hospital in Region VIII and none of the 
Table 2 Detection of viral pathogens from children hospitalized with severe pneumonia, Eastern Visayas Regional Medical Center, May 2008 to May 2009

\begin{tabular}{|c|c|c|c|c|c|c|c|c|c|c|c|c|c|c|c|c|}
\hline & & FluA & FluB & RSV-A & RSV-B & hMPV & PIVs & HRV-A & HRV-B & HRV-C & HCoV-OC43 & HCoV-NL63 & AdVs & HBoV & WU & $\mathrm{KI}$ \\
\hline FluA & & 12 & 0 & 1 & 0 & 0 & 0 & 2 & 0 & 1 & 0 & 0 & 1 & 0 & 0 & 0 \\
\hline FluB & & - & 3 & 0 & 0 & 0 & 0 & 4 & 0 & 3 & 0 & 0 & 0 & 0 & 0 & 0 \\
\hline RSV-A & & - & - & 160 & 0 & 0 & 0 & 13 & 6 & 3 & 0 & 0 & 2 & 1 & 5 & 1 \\
\hline RSV-B & & - & - & - & 5 & 0 & 0 & 0 & 0 & 0 & 0 & 0 & 0 & 0 & 0 & 0 \\
\hline hMPV & & - & - & - & - & 17 & 0 & 1 & 0 & 2 & 0 & 0 & 1 & 0 & 0 & 1 \\
\hline PIVs & & - & - & - & - & - & 8 & 1 & 0 & 0 & 0 & 0 & 1 & 0 & 1 & 0 \\
\hline HRV-A & & - & - & - & - & - & - & 103 & 0 & 0 & 0 & 0 & 5 & 2 & 7 & 0 \\
\hline HRV-B & & - & - & - & - & - & - & - & 17 & 0 & 0 & 0 & 0 & 1 & 1 & 0 \\
\hline HRV-C & & - & - & - & - & - & - & - & - & 69 & 0 & 1 & 2 & 1 & 0 & 0 \\
\hline HCoV-OC43 & & - & - & - & - & - & - & - & - & - & 1 & 0 & 0 & 0 & 0 & 0 \\
\hline HCoV-NL63 & & - & - & - & - & - & - & - & - & - & - & 1 & 0 & 0 & 0 & 0 \\
\hline AdVs & & - & - & - & - & - & - & - & - & - & - & - & 15 & 0 & 0 & 1 \\
\hline $\mathrm{HBOV}$ & & - & - & - & - & - & - & - & - & - & - & - & - & 2 & 0 & 0 \\
\hline WUV & & - & - & - & - & - & - & - & - & - & - & - & - & - & 9 & 0 \\
\hline KIV & & - & - & - & - & - & - & - & - & - & - & - & - & - & - & 1 \\
\hline $\begin{array}{l}\text { Single virus } \\
\text { positive }\end{array}$ & 423 & 12 & 3 & 160 & 5 & 17 & 8 & 103 & 17 & 69 & 1 & 1 & 15 & 2 & 9 & 1 \\
\hline $\begin{array}{l}\text { Double virus } \\
\text { positive }\end{array}$ & 72 & 5 & 7 & 32 & 0 & 5 & 3 & 35 & 8 & 13 & 0 & 1 & 13 & 5 & 14 & 3 \\
\hline $\begin{array}{l}\text { Triple viruses } \\
\text { positive }\end{array}$ & 6 & 1 & 1 & 1 & 0 & 1 & 1 & 4 & 0 & 1 & 0 & 0 & 5 & 0 & 2 & 1 \\
\hline $\begin{array}{l}\text { Total Positive } \\
\text { Samples }\end{array}$ & 501 & 18 & 11 & 193 & 5 & 23 & 12 & 142 & 25 & 83 & 1 & 2 & 33 & 7 & 25 & 5 \\
\hline
\end{tabular}

Flu indicates influenzavirus; RSV, respiratory syncytial virus; hMPV, human metapneumovirus; PIV, parainfluenzavirus; HRV, human rhinovirus; HCoV, human coronavirus; AdVs, adenoviruses; HBoV, human bovavirus; WUV, human WU polyomavirus; KVl; human KI polyomavirus.

PIVs-positive cases consisted of 11 cases of PIV-3(single=7) and 1 case of PIV-1(single=1).

Detection of Triple viruses: FluA, HRv-A, and PIV=1 case, FluB, HRV-C, and AdV-5=1 case, hMPV, AdV, and KIV=1 case, HRV-A, AdV,and WUV=2 cases, HRV-A, RSV-A, and $\mathrm{AdV}=1$ case

"Discharged against medical advice-deteriorating" had readmitted, those cases were most likely deceased after discharge. The overall case fatality rate (CFR) was $10.7 \%$ [88/ $819]$, and one or more viruses were detected in $52.2 \%$ [46/ 88] of these fatal cases (See Additional file 3: Outcome of the children hospitalized with severe pneumonia, Eastern Visayas Regional Medical Center, May 2008 to May 2009). There were fatalities in FluA-, RSV-A-, hMPV-, HRV-, $\mathrm{HCoV}-$, and $\mathrm{AdV}$-positive cases. In terms of CFRs among single virus-positive cases, FluA had the highest CFR (33.3\% [4/12]). The CFR of RSV-A was 7.5\% [12/160], whereas that of hMPV was 5.9\% [1/17]. Among HRVs, HRV-A (14.3\% [14/98]) and HRV-B (11.8\% [2/17]) had equivalent CFRs but HRV-C had a lesser CFR (5.6\% [4/ 71]). There were two cases positive for HCoVs: a patient with $\mathrm{HCoV}-\mathrm{OC} 43$ who was classified under the "died" category and one with HCoV-NL63 who was classified under "Discharged against medical advice-deteriorating" category. With respect to AdVs, one AdV-7-positive case was fatal, and two "Discharged against medical advicedeteriorating" patients were positive for AdV-3 and AdV-
7. There were two fatal cases each involving two viruses. One case was positive for HRV-A and AdVs, and the other was positive for HRV-B and RSV-A.

The risk of fatal outcome for each detected virus was evaluated on the basis of categorization in the "Discharged against medical advice-deteriorating" or "Died" category. First, cases with at least one virus $(8.6 \%$ [43/498]) were less likely to be associated with fatal outcomes compared to virus-negative cases $(13.9 \%$ [42/321]), but there was insufficient evidence of an association between fatal outcome and detection of at least one respiratory virus $(\mathrm{OR}=$ $0.62,95 \% \mathrm{CI}=0.5-1.0)$. Second, the risk of fatal outcome according to specific viruses was evaluated (Table 3). Among single virus-positive groups, being positive for FluA virus (odds $=0.50$ ) was associated with a greater risk of fatal outcome $(\mathrm{OR}=4.3,95 \% \mathrm{CI}=1.3-14.6)$ than nonFluA single virus positive (odds $=0.12$ ).

\section{Blood culture}

Blood culture samples were collected from 814 cases, 31 of which $(3.8 \%$ [31/814]) were positive in blood culture. 


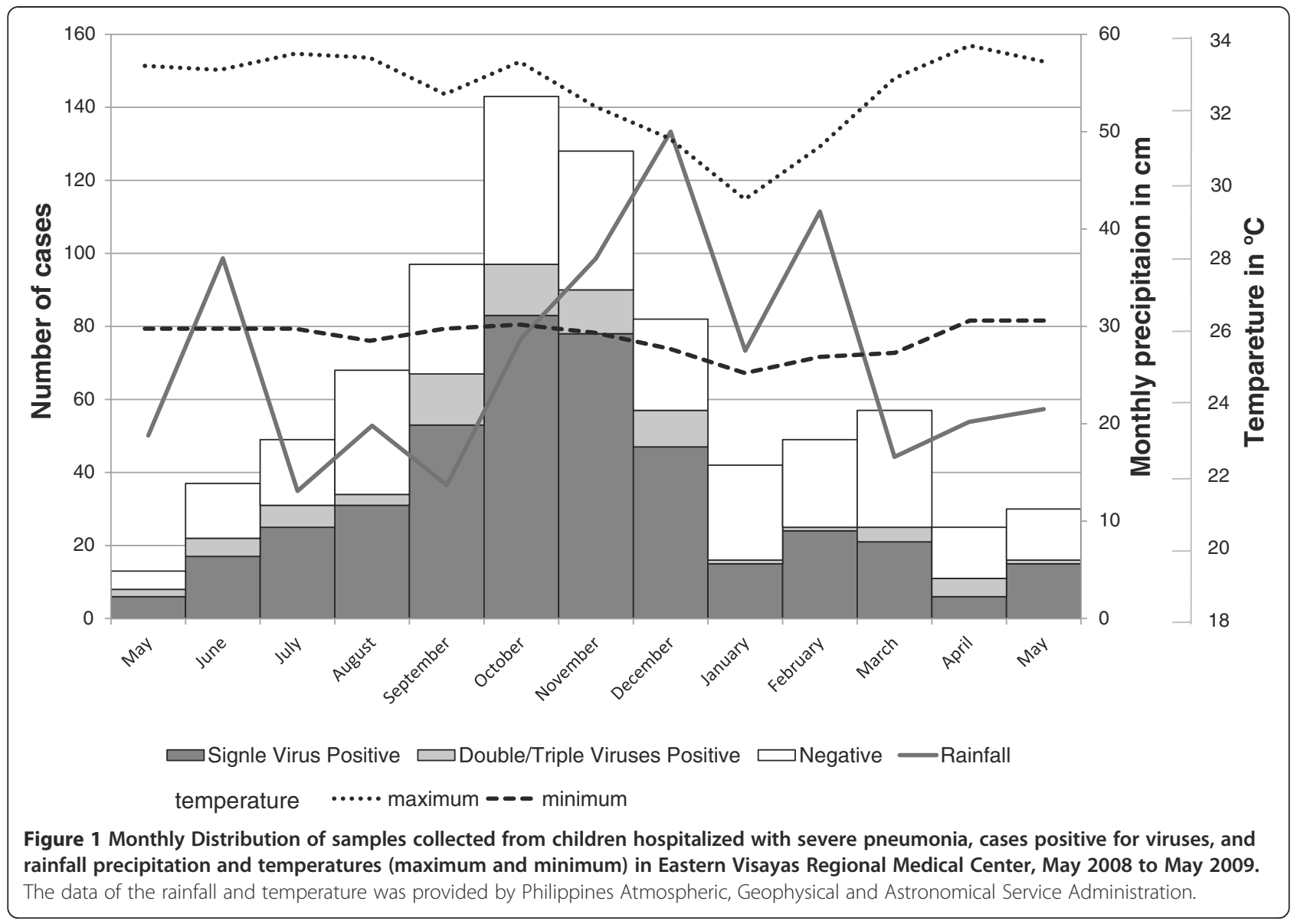

Among gram-positive cocci $(\mathrm{n}=15)$, there were Streptcoccus pneumonia $(\mathrm{n}=4)$, Staphylococcus aureus $(\mathrm{n}=4)$, Staphylococcus lugdunesis $(\mathrm{n}=3)$, Staphylococcus epidermidis $(\mathrm{n}=2)$, and Staphylococcus haemolyticus $(\mathrm{n}=2)$. Two isolates of $S$. aureus were methicillin resistant Staphylococcus aureus (MRSA). For gram-negative rods $(\mathrm{n}=3)$, there was one case for Haemophilus influenza, Enterobacter cloacae, and Salmonella C1. For glucose non-fermentes gram-negative rods $(\mathrm{n}=12)$, there were Burkholderia cepacia group $(\mathrm{n}=9)$, Pseudomonas aeruginosa $(\mathrm{n}=1)$, Pseudomonas stutzeri $(\mathrm{n}=1)$, and Shewanella putrefaciens $(\mathrm{n}=1)$. We confirmed isolation of Burkholderia cepacia group by $16 \mathrm{~S}$ rRNA sequencing. For gram-positive rods, there was Bacillus species $(n=1)$. There were four fatal cases among bacterial culturepositive cases, including B. cepacia group $(\mathrm{n}=3)$ and MRSA ( $\mathrm{n}=1)$, and one "Discharged against medical advice-deteriorating" case that was positive for MRSA $(\mathrm{n}=1)$. There were concomitant viral infections in samples positive for S. pneumoniae (FluB and HRV-A, $\mathrm{n}=1$ ), S. aureus (HRV-C and RSV-A, $\mathrm{n}=1$; RSV-A and $\mathrm{KIV}, \mathrm{n}=1$ ), MRSA (HRV-A, $\mathrm{n}=2$; HRV-A and AdV-2, $\mathrm{n}=1$ ), $H$. influenzae (HRV-A, $\mathrm{n}=1$ ), and $P$. aeruginosa (RSV-A, $\mathrm{n}=1$ ).

\section{Discussion}

Our study highlighted the potential importance of viruses as pathogens of community-acquired pneumonia among hospitalized children in the Philippines. The CFR in our study setting was as high as $8 \%$, which indicated that childhood pneumonia is still an important cause of death in the Philippines. We conducted our current study following the IMCI guideline, because IMCI has been implemented in various developing countries for nearly 20 years [31] as well as we also investigated the causative pathogens in those hospitalized children. Because, the IMCI approach toward childhood pneumonia focuses on bacterial infection, mainly through the empirical use of antibacterial drugs; however, the approach to the management of viral infections is not included in IMCI [19]. Furthermore, IMCI was developed on the basis of etiological studies conducted before 1990, when the detection methods for viral pathogens were suboptimal [32-34]. However, modern molecular methods, such as PCR exhibits higher sensitivity in virus detection. In addition, these methods facilitate the discovery of several new viruses as possible etiological agents for respiratory infection [6-13]. Using these methods, at least one virus was detected in $60.8 \%$ of cases in this study. Recent 


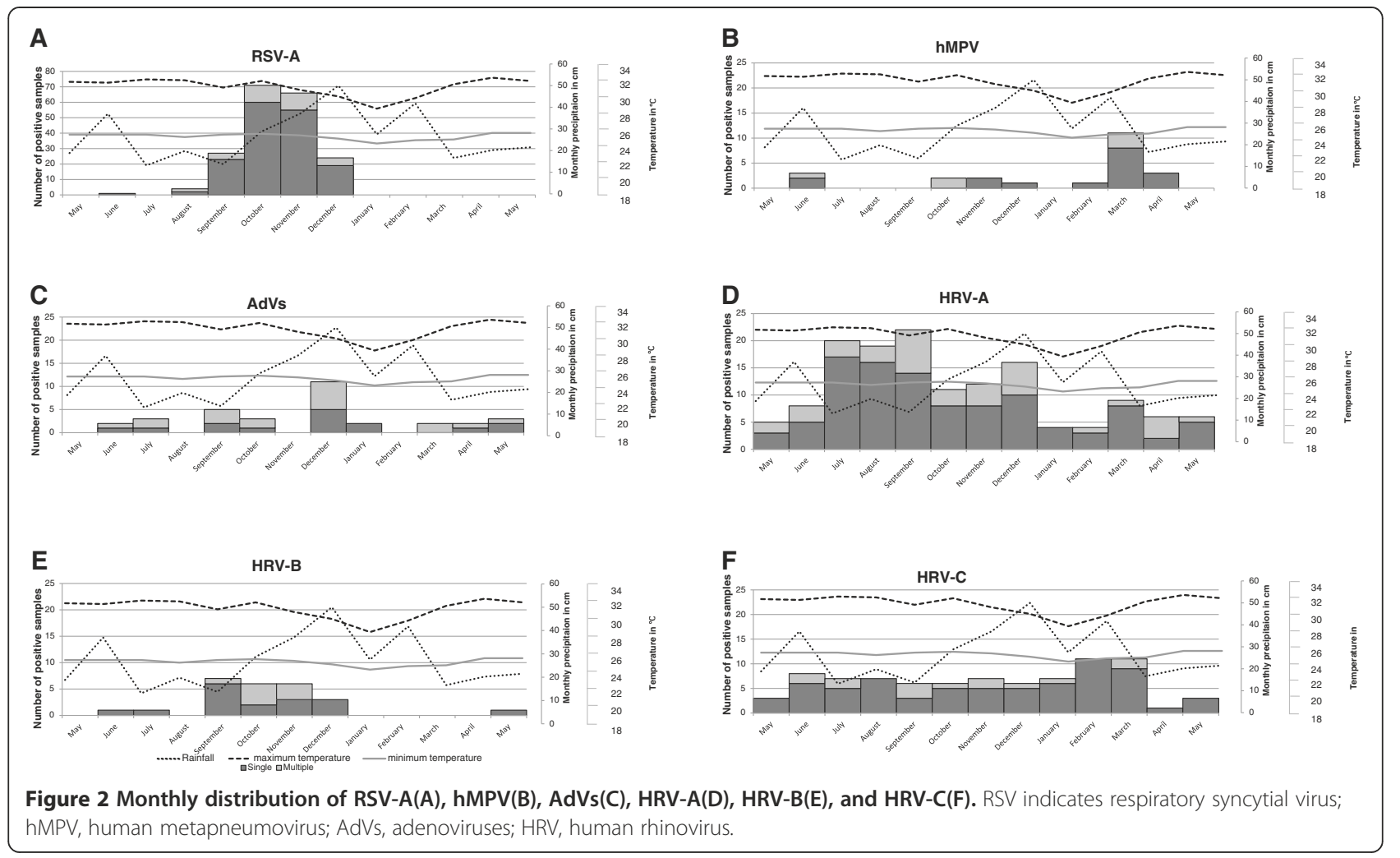

etiological studies also detected viruses in more than $50 \%$ of cases in similar settings $[35,36]$.

Although we have demonstrated an important potential role of viral pathogens, economical and effective options for the prevention and treatment of viral infections that are practical to implement in developing

Table 3 Odds and odds ratio for being fatal outcome among children hospitalized with severe pneumonia, Eastern Visayas Regional Medical Center, May 2008 to May 2009

\begin{tabular}{|c|c|c|c|c|c|c|c|}
\hline \multicolumn{8}{|c|}{ Odds ${ }^{\#}$} \\
\hline \multirow[b]{2}{*}{ FluA } & \multicolumn{2}{|c|}{$\begin{array}{l}\text { Single Virus } \\
\text { Positve Cases }\end{array}$} & \multicolumn{2}{|c|}{$\begin{array}{l}\text { Multiple Viruses } \\
\text { Positve Cases }\end{array}$} & \multicolumn{2}{|c|}{$\begin{array}{l}\text { Virus Negative } \\
\text { Cases }\end{array}$} & \multirow{2}{*}{$\begin{array}{l}\begin{array}{l}\text { OR }^{\$} \\
(95 \% ~ C l)\end{array} \\
4.3(1.3-14.6)\end{array}$} \\
\hline & $4 / 12$ & 0.50 & $0 / 6$ & 000 & $84 / 801$ & 0.12 & \\
\hline SSV-A & $12 / 160$ & 0.08 & $1 / 33$ & 0.03 & $75 / 626$ & 0.14 & $0.6(0.3-1.2)$ \\
\hline hMPV & $1 / 17$ & 0.06 & $0 / 6$ & 0.00 & $87 / 79$ & 0.12 & $0.5(0.1-3.9)$ \\
\hline RV-A & $15 / 103$ & 0.17 & $2 / 39$ & 0.05 & $71 / 6$ & 0.12 & $1.5(0.9-2.7)$ \\
\hline HRV-B & $2 / 17$ & 0.13 & $1 / 8$ & 0.14 & $85 / 794$ & 0.12 & $1.1(0.3-4.9)$ \\
\hline HRV-C & $4 / 69$ & 0.06 & $0 / 14$ & 0.00 & $84 / 736$ & 0.13 & $0.5(0.2-1.4)$ \\
\hline AdVs & $3 / 15$ & 0.25 & $2 / 18$ & 0.13 & $83 / 786$ & 0.12 & $2.1(0.6-7.6)$ \\
\hline
\end{tabular}

Flu indicates influenzavirus; RSV, respiratory syncytial virus; hMPV, human metapneumovirus; HRV, human rhinovirus; AdVs, adenoviruses.

"Fatal outcome is defined as either in "Discharged against medical adviceDeteriorated" or "Died".

${ }^{\text {S }}$ Single virus positive cases for the virus were compared with all other cases which may include multiple virus positive and virus negative cases. countries are unavailable. HRV- and RSV-positive cases accounted for approximately $55 \%$ of our study population and had significant effects including those on mortality. However, no effective and safe vaccines or antiviral drugs for these viruses are currently available [37]. The monoclonal RSV antibody for prophylaxis has been used for high-risk infants in developed countries, but this antibody is far too expensive to be used in developing countries [38]. FluA had the highest CFR and was a significant risk factor for fatal outcome, which suggests its potential high mortality impact during larger epidemics. Antiviral drugs such as neuraminidase inhibitors and vaccines for influenza are widely available and used in developed countries; however, they are not affordable in most of the developing countries [39]. To reduce childhood mortality due to viral pneumonia, feasible and inexpensive management strategies, such as triaging hypoxic patients with using a pulse oximeter and administering early treatment with oxygen, should be urgently developed [40].

Although we previously demonstrated the presence of novel viruses in the Philippines [14], our current study provided additional insight on novel viruses. One of the significant findings was the detection of HRV-C. In previous studies, the impact of HRV-C on morbidity and mortality was similar to that of HRV-A and was much greater than that of HRV-B [41-43]. In the present study, 
HRV-C, the prevalence of which was less than that of HRV-A and greater than that of HRV-B, was detected in $10.1 \%$ of the total cases and in three fatal cases. These results suggest that HRV-C could be an important viral pathogen in the cause of severe childhood pneumonia in the Philippines. However, its etiological role is still controversial because this virus has also been detected in healthy individuals [42]. Further studies are necessary to define the role of HRV-C in childhood pneumonia. Another novel virus that shares similar epidemiological and clinical features with RSV in industrialized countries is hMPV [44]. Previous studies in other developing countries indicated that the incidence of hMPV was lower than that of RSV [35,36,45]. However, we observed a fatal case of hMPV which might have an impact in our study setting. A series of $\mathrm{HCoVs}$ have been discovered by recent techniques [7-9]. Although none of the $\mathrm{HCoV}$-positive cases exhibited improvement during hospitalization, the number of positive cases was very small. Conversely, there was no fatal case among those positive for newly discovered DNA viruses including $\mathrm{HBoV}$, WUV, and KIV which suggest that their impact in our study is insignificant. However, their severity should be carefully interpreted because of the small number of positive cases for these viruses.

Studies on childhood pneumonia were conducted in the Philippines in the 1980s and 1990s [32,33,46]. In addition to those previous studies, subtyping of viral genetic information revealed group-specific epidemiology. Tupasi et al. demonstrated that RSV was the most common viral cause among children admitted with acute lower respiratory infection in the Philippines [33]. This was consistent with our present study as well as with other recent studies in developing countries $[35,36,45,47]$. RSV can be classified into two major groups; however, their proportions may change during epidemics [48]. Similarly, we demonstrated that the increase in the number of cases between September and December 2008 was primarily due to RSV-A, although RSV-B was also present in the early stage of the epidemic. We may further need to assess the RSV itself to understand the circulation dynamics of the virus [49]. On the contrary, Capeding et al. demonstrated that AdVs were also important viral pathogens in the Philippines [46]. We observed clustering of AdV-7 in genus B and AdV-6 in genus $C$, both of which are known to cause respiratory infections of varying severities among children [50]. As each genus of AdVs has different clinical and epidemiological features [51], genetic classification will help us understand the epidemiology of AdVs in tropical climates.

Bacteremia was observed in $3.8 \%$ of our cases, and this rate is similar to our previous findings in the Philippines $(2.9 \%$ and $5 \%)$ [20,22]. In addition to two major bacterial pathogens, S. pneumoniae $(\mathrm{n}=4)$ and $H$. influenzae $(\mathrm{n}=1)$, the most commonly isolated bacteria was B. cepacia group $(\mathrm{n}=9)$. B. cepacia is a habitant of the natural environment, but can cause severe infection in the hospital settings especially among immunocompromised patients in ICU $[52,53]$. Since B. cepacia infection in the community is rare $[54,55]$ and the samples were collected upon admission, it is more likely that those isolates of B. cepacia group are the contaminants due to contaminated sampling devices, such as disinfectant products [56], rather than causative bacteria pathogen for the pneumonia. However, it should be noted that 3 of those B. cepacia group positive-cases died. However, further investigation on the pathogenicity of the $B$. сеpacia in our study setting is required.

We might have underestimated the incidence of bacterial pneumonia since prior antibiotic use was observed among 32.4\% [264/814] of the enrolled cases. However, a recent study indicated that the prevalence of bacteremia among children with community-acquired pneumonia in the emergency department was as low as 2.1\% [57]. Unlike viral isolation, there is no "gold standard" for the diagnosis of bacterial pneumonia among children [58]. Blood culture is widely performed, but its sensitivity is as low as 1-3\% [59]. Bacteria cultured from the nasopharynx or throat do not always represent the pathogens in the lungs, as it may include the normal flora of the nose or throat. Lung tap provides an accurate diagnosis of childhood pneumonia [60], but it is an invasive procedure, difficult to perform aseptically, and therefore it is not commonly practiced in developing countries to avoid any iatrogenic complication due to the procedure itself.

The treatment approach of IMCI recommends the empirical use of antibacterial drugs [19], but there is a dilemma of the overuse of antibiotics that increases the emergence of drug resistance. Moreover, antibiotics can be purchased without prescription in the Philippines. For S. pneumoniae, all three invasive isolates were susceptible to penicillin, as reported in a previous study in Bohol, Philippines [61]. However, two cases with MRSA did not exhibited improvement during hospitalization. Community-acquired MRSA is a growing problem in developing countries [62]. As IMCI encourages vaccine and antibiotic use for bacterial infections, continuous monitoring of serotype distribution and drug susceptibility is essential for devising a local and cost-effective strategy against childhood pneumonia.

There are some limitations of our study. Firstly, the detection of viruses by molecular techniques may not necessarily indicate that the detected virus is a causative agent of respiratory symptoms since it does not fulfill Koch's postulate. We understand that the gold standard for the diagnosis of viral infection is virus isolation; however, 
many novel viruses cannot be isolated, and demonstrating the presence of the viral genome is the only available detection method. On the other hand, we identified multiple viruses in different combinations especially among patients positive for HBoV, WUV, and KIV (Table 2). WUV and KIV are members of Polyomaviridae that frequently cause latent infection along with reactivation by immunosupression [63]. Their pathogenicity needs to be elucidated with further epidemiological and clinical studies including appropriate "healthy" control groups. Secondly, we were not able to obtain the demographic information of those who refused to participate in the study due to ethical concerns. The proportion of very severe pneumonia among those who refused to participate was smaller than that of admitted cases, which may have led to an underestimation of the severity of the disease. Thirdly, our study was conducted in the only referral hospital in the region. Therefore, our study population may represent only severe and very severe cases with access to healthcare facilities in the study area. This may have resulted in the underestimation of some etiologies. FluA had the highest CFR, but its prevalence was low. This may be due to the reason that the time interval between onset and admission was 4 days, whereas the viral titer of FluA in respiratory specimens was highest within 48 hours of onset [64].

\section{Conclusion}

Our study demonstrates a potentially important role for viral pathogens in the etiology of severe pneumonia among the children in the Philippines. Our findings suggest that viral etiologies should be always kept in mind while developing effective strategies to reduce child pneumonia-related deaths in developing countries.

\section{Additional files}

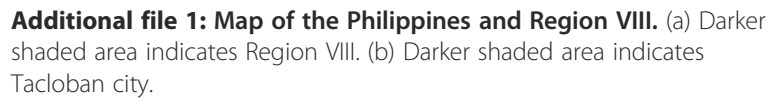

Additional file 2: Age distribution of children hospitalized with severe pneumonia in Eastern Visayas Regional Medical Center, May 2008 to May 2009.

Additional file 3: Outcome of the children hospitalized with severe pneumonia, Eastern Visayas Regional Medical Center, May 2008 to May 2009. Flu indicates influenzavirus; RSV, respiratory syncytial virus; hMPV, human metapneumovirus; PIVs, parainfluenzavirus; HRV, human rhinovirus; HCoV, human coronavirus; AdVs, adenoviruses; HBoV, human bovavirus; WUV, human WU polyomavirus; KVI; human KI polyomavirus.

\section{Abbreviations}

Flu: Influenza virus; RSV: Respiratory syncytial virus; hMPV: Human metapneumovirus; PIV: Parainfluenzavirus; HRV: Human rhinovirus; HCoV: Human coronavirus; AdVs: Adenoviruses; HBoV: Human bovavirus; WUV: Human WU polyomavirus; KVI: Human KI polyomavirus; IMCI: Integrated Management of Childhood IIness; MIC: Minimum inhibitory concentration; EQAS: External Quality Assurance System.

\section{Competing interests}

The authors declare that they have no competing interests.

\section{Authors' contributions}

$A S, S L, R O$, and $H O$ conceived the study and designed it together with FY, $N F, H G, L S$, and RA. AS, YF, and NF established viral detection methods, and $A S, Y F, N F$, and HG performed the test. LS and MM established and performed detection analysis for bacteria. RT performed statistical analysis. AS drafted the manuscript with assistance of SL and HO. All authors contributed to the final version of the manuscript, read and approved it.

\section{Acknowledgements}

This work was supported by the Japan Initiative for Global Research Network on Infectious Diseases (J-GRID) through the Tohoku-RITM Collaborating Center on Emerging and Reemerging Diseases. We thank our colleagues at EVRMC, RITM, and the Department of Virology Tohoku University Graduate School of Medicine for technical assistance. We especially thank Dr. Michiko Okamoto, Dr. Nobuko Sato and Dr. Chandra Nath Roy for technical assistance.

\section{Author details}

'Department of Virology, Tohoku University Graduate School of Medicine, 2-1 Seiryo-machi, Aoba-ku, Sendai 980-8575, Japan. ${ }^{2}$ Research Institute for Tropical Medicine, Department of Health Compound, FILINVEST Corporate City, Alabang, Muntinlupa City, Philippines. ${ }^{3}$ Collaborating Research Center for Emerging and Reemerging Infectious Diseases, Department of Health Compound, FILINVEST Corporate City, Alabang, Muntinlupa City, Philippines.

Received: 29 June 2011 Accepted: 18 October 2012

Published: 23 October 2012

\section{References}

1. You D, Wardlaw T, Salama P, Jones G: Levels and trends in under-5 mortality, 1990-2008. Lancet 2010, 375(9709):100-103.

2. Black RE, Cousens S, Johnson HL, Lawn JE, Rudan I, Bassani DG, Jha P, Campbell H, Walker CF, Cibulskis R, et al: Global, regional, and national causes of child mortality in 2008: a systematic analysis. Lancet 2010, 375 (9730):1969-1987.

3. UNICEF/WHO: Pneumonia: The forgotten killer of children.; 2006

4. Rudan I, Boschi-Pinto C, Biloglav Z, Mulholland K, Campbell H: Epidemiology and etiology of childhood pneumonia. Bull World Health Organ 2008, 86(5):408-416.

5. Arifeen SE, Hoque DM, Akter T, Rahman M, Hoque ME, Begum K, Chowdhury EK, Khan R, Blum LS, Ahmed S, et al: Effect of the integrated management of childhood illness strategy on childhood mortality and nutrition in a rural area in Bangladesh: a cluster randomised trial. Lancet 2009, 374(9687):393-403.

6. van den Hoogen BG, de Jong JC, Groen J, Kuiken T, de Groot R, Fouchier RA, Osterhaus AD: A newly discovered human pneumovirus isolated from young children with respiratory tract disease. Nat Med 2001, 7(6):719-724.

7. van der Hoek L, Pyrc K, Jebbink MF, Vermeulen-Oost W, Berkhout RJ, Wolthers KC, Wertheim-van Dillen PM, Kaandorp J, Spaargaren J, Berkhout B: Identification of a new human coronavirus. Nat Med 2004, 10(4):368-373.

8. Esper F, Weibel C, Ferguson D, Landry ML, Kahn JS: Evidence of a novel human coronavirus that is associated with respiratory tract disease in infants and young children. J Infect Dis 2005, 191(4):492-498.

9. Woo PC, Lau SK, Chu CM, Chan KH, Tsoi HW, Huang Y, Wong BH, Poon RW, Cai JJ, Luk WK, et al: Characterization and complete genome sequence of a novel coronavirus, coronavirus HKU1, from patients with pneumonia. J Virol 2005, 79(2):884-895.

10. Lamson D, Renwick N, Kapoor V, Liu Z, Palacios G, Ju J, Dean A, St George K, Briese T, Lipkin Wl: MassTag polymerase-chain-reaction detection of respiratory pathogens, including a new rhinovirus genotype, that caused influenza-like illness in New York State during 2004-2005. J Infect Dis 2006, 194(10):1398-1402.

11. Allander T, Tammi MT, Eriksson M, Bjerkner A, Tiveljung-Lindell A, Andersson $B$ : Cloning of a human parvovirus by molecular screening of respiratory tract samples. Proc Natl Acad Sci U S A 2005, 102(36):12891-12896.

12. Allander T, Andreasson K, Gupta S, Bjerkner A, Bogdanovic G, Persson MA, Dalianis T, Ramqvist T, Andersson B: Identification of a third human polyomavirus. J Virol 2007, 81(8):4130-4136. 
13. Gaynor AM, Nissen MD, Whiley DM, Mackay IM, Lambert SB, Wu G, Brennan DC, Storch GA, Sloots TP, Wang D: Identification of a novel polyomavirus from patients with acute respiratory tract infections. PLOS Pathog 2007, 3(5):e64.

14. Furuse Y, Suzuki A, Kishi M, Galang HO, Lupisan SP, Olveda RM, Oshitani H: Detection of novel respiratory viruses from influenza-like illness in the Philippines. J Med Virol 2010, 82(6):1071-1074.

15. Philippines Poverty Statistics: http://www.nscb.gov.ph/poverty/ 2006_05mar08/table_1.asp.

16. Demographic and Health Survey, Republic of the Philippines: http://www.census.gov.ph.

17. WHO/UNICEF: Model IMCI handbook: Integrated management of childhood illness. 2005.

18. Society PP (Ed): Clinical Practice Guidelines In The Evaluation and Management of Pediatric Community Acquired Pneumonia. 2008.

19. Gove S: Integrated management of childhood illness by outpatient health workers: technical basis and overview. The WHO working group on guidelines for integrated management of the sick child. Bull World Health Organ 1997, 75(Suppl 1):7-24.

20. Quiambao BP, Ruutu PJ, Ladesma EA, Gozum LS, Inobaya MT, Lupisan SP, Sombrero LT, Romano V, Simoes EA: Pneumonia among young infants in rural Southeast Asia (Bohol Island, Philippines). Trop Med Int Health 2009, 14(12):1457-1466.

21. Lupisan SP, Ruutu P, Erma Abucejo-Ladesma P, Quiambao BP, Gozum L, Sombrero LT, Romano V, Herva E, Riley I, Simoes EA: Predictors of death from severe pneumonia among children 2-59 months old hospitalized in Bohol, Philippines: implications for referral criteria at a first-level health facility. Trop Med Int Health 2007, 12(8):962-971.

22. Lupisan SP, Herva E, Sombrero LT, Quiambao BP, Capeding MR, Abucejo PE, Esparar G, Arcay J, Ruutu P: Invasive bacterial infections of children in a rural province in the central Philippines. Am J Trop Med Hyg 2000, 62(3):341-346

23. Lupisan SP, Ruutu P, Abucejo-Ladesma PE, Quiambao BP, Gozum L, Sombrero LT, Romano V, Riley I, Simoes EA: Central nervous system infection is an important cause of death in underfives hospitalised with World Health Organization (WHO) defined severe and very severe pneumonia. Vaccine 2007, 25(13):2437-2444

24. Bellau-Pujol S, Vabret A, Legrand L, Dina J, Gouarin S, PetitjeanLecherbonnier J, Pozzetto B, Ginevra C, Freymuth F: Development of three multiplex RT-PCR assays for the detection of 12 respiratory RNA viruses. J Virol Methods 2005, 126(1-2):53-63.

25. Kiang D, Yagi S, Kantardjieff KA, Kim EJ, Louie JK, Schnurr DP: Molecular characterization of a variant rhinovirus from an outbreak associated with uncommonly high mortality. J Clin Virol 2007, 38(3):227-237

26. Kiang D, Kalra I, Yagi S, Louie JK, Boushey H, Boothby J, Schnurr DP: Assay for $5^{\prime}$ noncoding region analysis of all human rhinovirus prototype strains. J Clin Microbiol 2008, 46(11):3736-3745.

27. Peret TC, Hall CB, Hammond GW, Piedra PA, Storch GA, Sullender WM, Tsou $C$, Anderson $L$ : Circulation patterns of group $A$ and $B$ human respiratory syncytial virus genotypes in 5 communities in North America. $J$ Infect Dis 2000, 181(6):1891-1896.

28. Savolainen C, Blomqvist S, Mulders MN, Hovi T: Genetic clustering of all 102 human rhinovirus prototype strains: serotype 87 is close to human enterovirus 70. J Gen Virol 2002, 83(Pt 2):333-340.

29. Casas I, Avellon A, Mosquera M, Jabado O, Echevarria JE, Campos RH, Rewers M, Perez-Brena P, Lipkin Wl, Palacios G: Molecular identification of adenoviruses in clinical samples by analyzing a partial hexon genomic region. J Clin Microbiol 2005, 43(12):6176-6182.

30. Tamura K, Dudley J, Nei M, Kumar S: MEGA4: Molecular Evolutionary Genetics Analysis (MEGA) software version 4.0. Mol Biol Evol 2007 24(8):1596-1599.

31. Multi-country evaluation: http://www.who.int/imci-mce/.

32. Ruutu P, Halonen P, Meurman O, Torres C, Paladin F, Yamaoka K, Tupasi TE: Viral lower respiratory tract infections in Filipino children. $J$ Infect Dis 1990, 161(2):175-179.

33. Tupasi TE, Lucero MG, Magdangal DM, Mangubat NV, Sunico ME, Torres CU, de Leon LE, Paladin JF, Baes L, Javato MC: Etiology of acute lower respiratory tract infection in children from Alabang, Metro Manila. Rev Infect Dis 1990, 12(Suppl 8):S929-939.

34. Tupasi TE, de Leon LE, Lupisan S, Torres CU, Leonor ZA, Sunico ES, Mangubat NV, Miguel CA, Medalla F, Tan ST, et al: Patterns of acute respiratory tract infection in children: a longitudinal study in a depressed community in Metro Manila. Rev Infect Dis 1990, 12(Suppl 8):S940-949.

35. Yoshida LM, Suzuki M, Yamamoto T, Nguyen HA, Nguyen CD, Nguyen AT, Oishi K, Vu TD, Le TH, Le MQ, et al: Viral pathogens associated with acute respiratory infections in central vietnamese children. Pediatr Infect Dis J 2009, 27:75-77.

36. Berkley JA, Munywoki $P$, Ngama M, Kazungu S, Abwao J, Bett A, Lassauniere $R$, Kresfelder T, Cane PA, Venter $M$, et al: Viral etiology of severe pneumonia among Kenyan infants and children. JAMA 2010, 303 (20):2051-2057.

37. Power UF: Respiratory syncytial virus (RSV) vaccines-two steps back for one leap forward. J Clin Virol 2008, 41(1):38-44.

38. Fitzgerald DA: Preventing RSV bronchiolitis in vulnerable infants: the role of palivizumab. Paediatr Respir Rev 2009, 10(3):143-147.

39. Oshitani H, Kamigaki T, Suzuki A: Major issues and challenges of influenza pandemic preparedness in developing countries. Emerg Infect Dis 2008, 14(6):875-880

40. Duke T, Wandi F, Jonathan M, Matai S, Kaupa M, Saavu M, Subhi R, Peel D: Improved oxygen systems for childhood pneumonia: a multihospital effectiveness study in Papua New Guinea. Lancet 2008, 372(9646):1328-1333

41. Lau SK, Yip CC, Lin AW, Lee RA, So LY, Lau YL, Chan KH, Woo PC, Yuen KY: Clinical and molecular epidemiology of human rhinovirus $C$ in children and adults in Hong Kong reveals a possible distinct human rhinovirus $\mathrm{C}$ subgroup. J Infect Dis 2009, 200(7):1096-1103.

42. Calvo C, Casas I, Garcia-Garcia ML, Pozo F, Reyes N, Cruz N, Garcia-Cuenllas L, Perez-Brena P: Role of rhinovirus c respiratory infections in sick and healthy children in Spain. Pediatr Infect Dis J 2010, 29:717-720.

43. Xiang Z, Gonzalez R, Xie Z, Xiao Y, Liu J, Chen L, Liu C, Zhang J, Ren L, Vernet $G$, et al: Human rhinovirus $C$ infections mirror those of human rhinovirus $A$ in children with community-acquired pneumonia. J Clin Virol 2010, 49(2):94-99.

44. van den Hoogen BG, Osterhaus DM, Fouchier RA: Clinical impact and diagnosis of human metapneumovirus infection. Pediatr Infect Dis J 2004, 23(1 Suppl):S25-32.

45. Mathisen M, Strand TA, Sharma BN, Chandyo RK, Valentiner-Branth P, Basnet S, Adhikari RK, Hvidsten D, Shrestha PS, Sommerfelt H: RNA viruses in community-acquired childhood pneumonia in semi-urban Nepal; a cross-sectional study. BMC Med 2009, 7:35.

46. Capeding MR, Sombrero LT, Paladin FJ, Suzuki H, Numazaki Y, Saniel MC Etiology of acute lower respiratory infection in Filipino children under five years. Southeast Asian J Trop Med Public Health 1994, 25(4):684-687.

47. Berkley JA, Versteeg AC, Mwangi I, Lowe BS, Newton CR: Indicators of acute bacterial meningitis in children at a rural Kenyan district hospital. Pediatrics 2004, 114(6):e713-719.

48. Reiche J, Schweiger B: Genetic variability of group A human respiratory syncytial virus strains circulating in Germany from 1998 to 2007. J Clin Microbiol 2009, 47(6):1800-1810.

49. Gaunt ER, Jansen RR, Poovorawan $Y$, Templeton $K E$, Toms GL, Simmonds $P$ Molecular epidemiology and evolution of human respiratory syncytial virus and human metapneumovirus. PLOS ONE 2011, 6(3):e17427.

50. Hayashi S, Hogg JC: Adenovirus infections and lung disease. Curr Opin Pharmacol 2007, 7(3):237-243.

51. Berk AJ: Adenoviridae:The Viruses and Their Replication. In Fields Virology. 5th edition. Edited by Knipe DM, Howley PM. Philadelphia: Lippincott Williams \& Wilkins; 2007:2355-2394.

52. Dizbay M, Tunccan OG, Sezer BE, Aktas F, Arman D: Nosocomial Burkholderia cepacia infections in a Turkish university hospital: a five-year surveillance. J Infect Dev Ctries 2009, 3(4):273-277.

53. Loukil C, Saizou C, Doit C, Bidet P, Mariani-Kurkdjian P, Aujard Y, Beaufils F, Bingen E: Epidemiologic investigation of Burkholderia cepacia acquisition in two pediatric intensive care units. Infect Control Hosp Epidemiol 2003, 24(9):707-710

54. Govan JR, Hughes JE, Vandamme P: Burkholderia cepacia: medical, taxonomic and ecological issues. J Med Microbiol 1996, 45(6):395-407.

55. Waterer GW, Jones CB, Wunderink RG: Bacteremic community-acquired pneumonia in an immunocompetent adult due to Burkholderia cepacia. Chest 1999, 116(6):1842-1843.

56. Romero-Gomez MP, Quiles-Melero MI, Pena Garcia P, Gutierrez Altes A, Garcia de Miguel MA, Jimenez C, Valdezate S, Saez Nieto JA: Outbreak of 
Burkholderia cepacia bacteremia caused by contaminated chlorhexidine in a hemodialysis unit. Infect Control Hosp Epidemiol 2008, 29(4):377-378.

57. Shah SS, Dugan MH, Bell LM, Grundmeier RW, Florin TA, Hines EM, Metlay

JP: Blood cultures in the emergency department evaluation of childhood pneumonia. Pediatr Infect Dis J 2011, 30(6):475-479.

58. Lynch T, Bialy L, Kellner JD, Osmond MH, Klassen TP, Durec T, Leicht R, Johnson DW: A systematic review on the diagnosis of pediatric bacterial pneumonia: when gold is bronze. PLOS ONE 2010, 5(8):e11989.

59. Ruuskanen O, Mertsola J: Childhood community-acquired pneumonia. Semin Respir Infect 1999, 14(2):163-172.

60. Vuori-Holopainen E, Salo E, Saxen H, Hedman K, Hyypia T, Lahdenpera R, Leinonen M, Tarkka E, Vaara M, Peltola H: Etiological diagnosis of childhood pneumonia by use of transthoracic needle aspiration and modern microbiological methods. Clin Infect Dis 2002, 34(5):583-590.

61. Sombrero L, Nissinen A, Esparar G, Lindgren M, Siira L, Virolainen A: Low incidence of antibiotic resistance among invasive and nasopharyngeal isolates of Streptococcus pneumoniae from children in rural Philippines between 1994 and 2000. Eur J Clin Microbiol Infect Dis 2008, 27(10):929935.

62. Nickerson EK, West TE, Day NP, Peacock SJ: Staphylococcus aureus disease and drug resistance in resource-limited countries in south and east Asia. Lancet Infect Dis 2009, 9(2):130-135.

63. Markowitz RB, Thompson HC, Mueller JF, Cohen JA, Dynan WS: Incidence of $B K$ virus and $J C$ virus viruria in human immunodeficiency virusinfected and -uninfected subjects. J Infect Dis 1993, 167(1):13-20.

64. Richman DD, Murphy BR, Baron S, Uhlendorf C: Three strains of influenza A virus ( $\mathrm{H} 3 \mathrm{~N} 2)$ : interferon sensitivity in vitro and interferon production in volunteers. J Clin Microbiol 1976, 3(3):223-226.

doi:10.1186/1471-2334-12-267

Cite this article as: Suzuki et al:: Respiratory viruses from hospitalized children with severe pneumonia in the Philippines. BMC Infectious

Diseases 2012 12:267.

\section{Submit your next manuscript to BioMed Central and take full advantage of:}

- Convenient online submission

- Thorough peer review

- No space constraints or color figure charges

- Immediate publication on acceptance

- Inclusion in PubMed, CAS, Scopus and Google Scholar

- Research which is freely available for redistribution 